University of Nebraska - Lincoln

DigitalCommons@University of Nebraska - Lincoln

$1-4-1996$

\title{
Immunological responses in the mouse host to a cloned antigen of Taeniacrassiceps
}

Dolores E. Hill

Beltsville Agricultural Research Center East, Beltsville

Dante S. Zarlenga

Beltsville Agricultural Research Center East, Beltsville

Follow this and additional works at: https://digitalcommons.unl.edu/usdaarsfacpub

Hill, Dolores E. and Zarlenga, Dante S., "Immunological responses in the mouse host to a cloned antigen of Taeniacrassiceps" (1996). Publications from USDA-ARS / UNL Faculty. 2245.

https://digitalcommons.unl.edu/usdaarsfacpub/2245

This Article is brought to you for free and open access by the U.S. Department of Agriculture: Agricultural Research Service, Lincoln, Nebraska at DigitalCommons@University of Nebraska - Lincoln. It has been accepted for inclusion in Publications from USDA-ARS / UNL Faculty by an authorized administrator of DigitalCommons@University of Nebraska - Lincoln. 


\title{
Immunological responses in the mouse host to a cloned antigen of Taenia crassiceps
}

\author{
Dolores E. Hill * , Dante S. Zarlenga \\ United Siates Department of Agriculture, Agricultural Research Service, Livestock and Poultry Sciences \\ Institute, Biosystematic Parasitology Laboratory, Beltsville Agricultural Research Center East, Beltsville, MD \\ 20720, USA
}

Received 18 May 1995; accepted 4 January 1996

\begin{abstract}
Adult female Swiss-Webster mice were immunized either intraperitoneally (IP) or subcutaneously (SQ) with cyst fluid or a genetically engineered fusion protein, Taenia crassiceps antigen 2-maltose binding protein (TCA2-MBP) from Taenia crassiceps metacestodes, or with live, non-budding cysts $\mathrm{SQ}$, and then challenged IP with $T$. crassiceps metacestodes and necropsied 9 weeks later. Numbers of peripheral blood eosinophils were increased after IP immunization, but were not increased after SQ immunization or with SQ cysts given before the challenge infection. Eosinophil numbers gradually decreased over the course of the experiment, and were not found in increased numbers in the blood or peritoneal cavity at necropsy. Antigen-specific antibody responses were seen at day 14 or 28 in IP and SQ immunized groups; IgG1 and IgG3 isotypes continued to increase over the course of the experiment. A significant protective response was induced by immunization with the cyst fluid ( $15 \pm 4, X \pm S E$ recovered larvae) or the TCA2-MBP $(22 \pm 12)$ given IP, but not SQ $(122 \pm 36 ; 207 \pm 53$, respectively) as measured by the numbers of larvae recovered at necropsy. Live cysts given SQ resulted in reduced numbers of cysts in the peritoneal cavity $(188 \pm 66)$, but was not as effective as cyst fluid or TCA2-MBP given IP. Locally (IP) induced immune responses may be involved in the development of the protective response to a challenge infection with $T$. crassiceps metacestodes.
\end{abstract}

Keywords: Taenia crassiceps; Cestode; Metacestode; Mouse host; Antibody isotype; Immunity; Fusion protein

\footnotetext{
* Corresponding author.
} 


\section{Introduction}

Metacestode infections of man and animals pose risks both in terms of health and economic losses. Taenia solium and Taenia saginata, cestode parasites of swine and cattle, respectively, are important because both utilize humans as the definitive host. In the case of $T$. solium, humans can also act as intermediate hosts for the metacestode stage, often with serious medical consequences, such as neurocysticercosis (Flisser and Larralde, 1986; Del Brutto and Sotelo, 1988).

Immunological and biochemical studies of these parasites are often limited due to the lack of parasite material from human hosts. Taenia crassiceps is a tapeworm parasite of rodents that is commonly used as a model system to study cestode infections involving metacestode infiltration of organ systems or tissues (Siebert et al., 1981; Hilwig and Cramer, 1983; Kalinna et al., 1989).

We have used this model system to investigate protective immune responses in mice to challenge infections with $T$. crassiceps cysts after immunization with three $T$. crassiceps antigen preparations, including a cloned peptide from $T$. crassiceps metacestodes linked to a maltose binding protein, designated TCA2-MBP (Taenia crassiceps antigen 2-maltose binding protein).

The purpose of the current study was to determine the usefulness of the cloned protein as a protective antigen in the mouse model of $T$. crassiceps infection in comparison to native cyst antigens, and to determine the humoral and granulocytic parameters associated with a resistant state in the mice. Antibody and eosinophil levels were monitored over the course of the experiment, and comparisons were made among treatment groups to determine if changes in specific antibody isotype responses and eosinophil levels in peripheral blood correlated with the development of resistance, and to determine the effect of immunization route on the development of the immune response against a challenge infection with $T$. crassiceps metacestodes.

\section{Materials and methods}

\subsection{Cyst collection and cyst fluid source}

Adult Swiss-Webster female mice were infected with 10-20 small, non-budding $T$. crassiceps cysts (maintained at the Beltsville Agricultural Research Center), and the infection was allowed to proceed for 2-3 months. Metacestodes were washed from the peritoneal cavity and incubated overnight in four changes of sterile RPMI 1640 media to remove host proteins, washed in phosphate buffered saline (PBS, pH 7.3), then resuspended in PBS containing $0.1 \%$ CHAPS detergent. Cysts were homogenized and centrifuged at $500 \times g$, and the supernatant was dialyzed (pore size 6000-8000) overnight at $4^{\circ} \mathrm{C}$ against three changes of PBS. The dialyzed cyst fluid was concentrated ten times in a Centricon (Amicon, Lexington, MA) concentrating unit with a $10 \mathrm{kDa}$ cutoff. Two milligrams of this material was passed through a $1 \mathrm{ml}$ syringe packed with a slurry of Sepharose CL4B-Protein A beads (Sigma Chemical, St. Louis, MO) to remove any remaining mouse IgG. The material which passed through the column was aliquoted and frozen at $-70^{\circ} \mathrm{C}$ until used. 


\subsection{Preparation of cloned antigen}

The maltose binding fusion protein, TCA2-MBP, was derived from a cDNA expression library using $T$. crassiceps metacestode mRNA (Rhoads et al., 1991). The 286 bp insert was subcloned into the Eco R1 site of pMAL-C2 generating a $46 \mathrm{kDa}$ maltose binding fusion protein (TCA2-MBP) upon induction with $0.1 \mathrm{mM}$ IPTG (isopropyl- $\beta$ D-thiogalactoside). Bacterial cells from an induced $500 \mathrm{ml}$ culture were pelleted and lysed in $50 \mathrm{ml}$ of a $20 \mathrm{mg} \mathrm{ml}^{-1}$ solution of lysozyme followed by freeze-thawing. After centrifugation $(2000 \times \mathrm{g}, 15 \mathrm{~min})$, the supernatant was mixed with an equal volume of $2 \times$ lysis buffer (10 mM phosphate, $0.5 \mathrm{M} \mathrm{NaCl}, 0.25 \%$ Tween-20, $10 \mathrm{mM}$ B-ME, 10 $\mathrm{mM}$ EGTA, $10 \mathrm{mM}$ EDTA) and passed over an amylose affinity column. The fusion protein was eluted from the column in $10 \mathrm{mM}$ maltose and collected in $1 \mathrm{ml}$ fractions. Aliquots $(2.5 \mu \mathrm{l})$ from each fraction were spotted onto a nitrocellulose filter and immunologically screened with a rabbit antibody made against the naturally derived protein, THFAS (Taenia hydatigena fraction ammonium sulfate precipitable; Rhoads et al., 1985). Positive fractions were pooled and concentrated using a Centricon filtration unit ( $10 \mathrm{kDa}$ cutoff) and stored frozen at $-70^{\circ} \mathrm{C}$. Preparation of control MBP (maltose binding protein) was essentially as above using pMAL-C2 transformed cells only. Column fractions were similarly screened using rabbit anti-MBP as the primary antibody. Fractions containing MBP were pooled, concentrated, and frozen at $-70^{\circ} \mathrm{C}$.

\subsection{Immunization procedure}

One hundred and ten 6-week-old female Swiss-Webster mice were divided into seven groups of ten and two groups of 20 , and immunized with antigens (cyst fluid, TCA2-MBP, control MBP) prepared as described above. Six groups of ten mice each were immunized subcutaneously (SQ) or intraperitoneally (IP) with $40 \mu \mathrm{g}$ of each antigen described above, in alum, three times, at 7 day intervals beginning on day 1 . A seventh group of ten mice were given five small (under $3 \mathrm{~mm}$ ), nonbudding cysts SQ on the back on day 1 only. Control groups ( 20 mice each) were immunized IP or SQ with saline in alum. All mice were given a challenge infection of five small nonbudding $T$. crassiceps cysts IP on day 21 except for half of each control group, which was left unchallenged.

\subsection{ELISA procedure}

Mice were bled biweekly throughout the experiment to monitor antigen-specific antibody titers and changes in antibody isotype using the Protein-A treated cyst fluid as antigen in an amplified antigen-specific enzyme linked immunosorbent assay (ELISA; Hill et al., 1994). The cyst fluid antigen was added to the wells of flat-bottomed Nunc microtiter plates (PGC Scientific, Gaithersburg, MD) at a concentration of $1 \mu \mathrm{g}$ protein per well. Test sera from immunized mice and reference standard sera (RSS), derived from a pool of non-immunized, unchallenged mice, were added to 24 wells each at a dilution of 1:10000. Goat-anti-mouse IgG1, IgG2a, IgG2b, IgG3, IgA, and IgM from the Mouse Isotyping Panel Kit (BioRad, Melville, NY) were added to triplicate wells as 
the second step antibody. In addition, goat anti-mouse IgG (Fc specific) was added to three wells, and three wells functioned as control wells to which saline was added instead of second step antibody. Next, rabbit anti-goat IgG bridging antibody $(\mathrm{H}+\mathrm{L}$ chain, Kirkegaard and Perry Labs, Gaithersburg, MD) was added to the wells, followed by rabbit peroxidase anti-peroxidase antibody (Jackson Immunoresearch Labs Inc., West Grove, PA). Peroxidase activity was indicated using the ABTS peroxidase substrate system (Kirkegaard and Perry Labs). Plates were read after adding substrate on a BioRad Model 450 Microplate Reader (BioRad, Melville, NY) set at $405 \mathrm{~nm}$. The data were analyzed using the ELISANALYSIS 1 system (Peterman and Butler, 1989) and the reference standard was assigned an activity of 100 ELISA units (EU) per undiluted milliliter for each measured isotype.

\subsection{Eosinophil counting procedure and necropsy}

Peripheral blood eosinophil numbers were monitored biweekly using a Unopette eosinophil staining kit (Becton-Dickinson, Rutherford, NJ), a Neubaur hemacytometer (Hausser Scientific, USA), and a Zeiss Universal microscope.

Mice were killed 9 weeks after the challenge infection. Cysticerci were collected by peritoneal washes, sedimented in PBS, and counted. PBS washes of the peritoneal cavity were centrifuged at $1000 \times g$ for 10 min to pellet cells. Smears were made on glass slides of the pelleted material. The slides were stained with Wright's stain and mounted with Permount (Fisher Scientific, Pittsburg, PA) for differential counting of cells. The resuspended pelleted material was stained for eosinophils and counted as above.

Granulomas were found in the peritoneal cavity in some animals at necropsy. These lesions, which were attached to the mesenteries and the lining of the peritoneal cavity, were removed, fixed, and thick sectioned as described by Hill et al. (1990), and examined.

Parasitological and immunological parameters were compared using analysis of variance with Duncan's multiple comparisons and expressed as mean and standard error. Differences were considered significant at $P<0.05$.

\section{Results}

\subsection{Immunizations}

Intraperitoneal immunization of Swiss-Webster adult female mice with cyst fluid or with TCA2-MBP resulted in a significant protective response against a challenge infection with $T$. crassiceps larval cysts as measured by the number of recovered IP cysts (Fig. 1A). A 93\% reduction in the number of recovered cysts was seen in animals immunized with TCA2-MBP $(22 \pm 12$ cysts, $X \pm S E)$, and a 95\% reduction in recovered cysts was seen in cyst fluid immunized animals (15 \pm 4$)$ when compared with challenged controls (334 \pm 78$)$.

Subcutaneous immunization with TCA2-MBP (207 \pm 53 ), cyst fluid (122 \pm 36$)$, or with nonbudding cysts $(188 \pm 66)$ resulted in reduced numbers of cysts when compared 


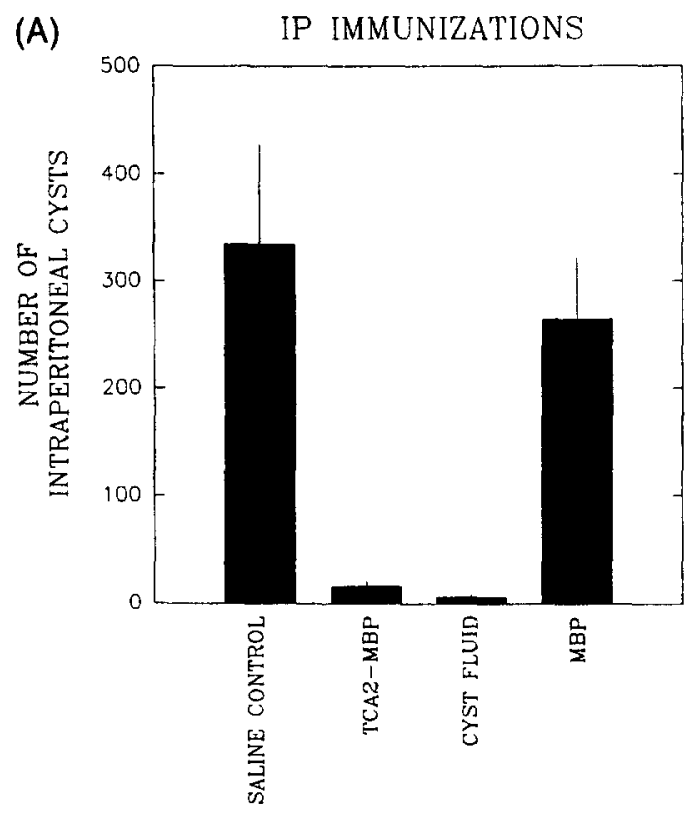

(B) SQ IMMUNIZATIONS

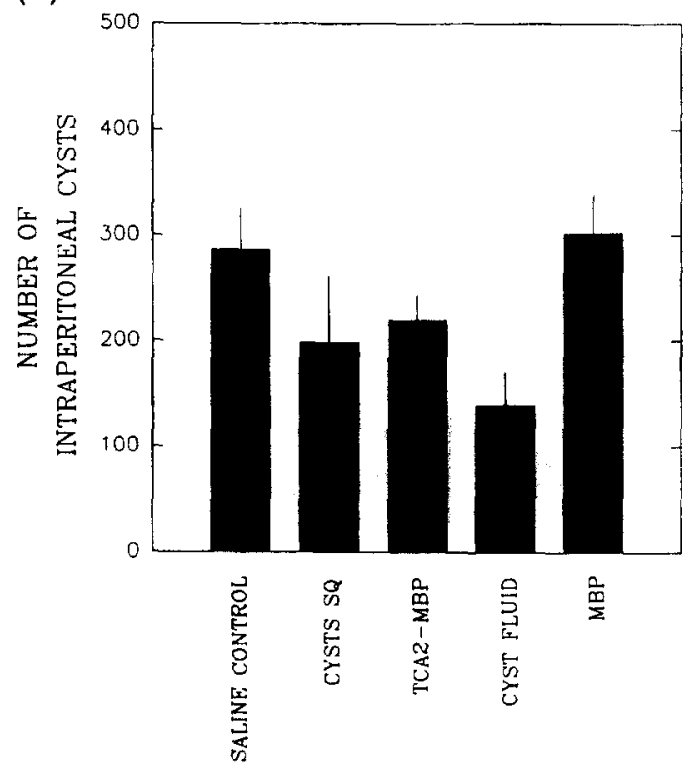

Fig. 1. Intraperitoneal (IP) cysts recovered at necropsy $(X, \mathrm{SE}, n=10)$ in mice immunized intraperitoneally (IP) (A) or subcutaneously (SQ) (B) with Taenia crassiceps antigen 2-maltose binding protein (TCA2-MBP), cyst fluid, MBP, and saline, all in alum and (B only) live, non-binding cysts. IP immunization with cyst fluid or TCA2-MBP resulted in significant reduction in IP cysts recovered at necropsy when compared with saline control. 
(A)

IgG ANTIBODY RESPONSES TO CYST FLUID ANTIGEN FROM IP IMMUNIZED MICE

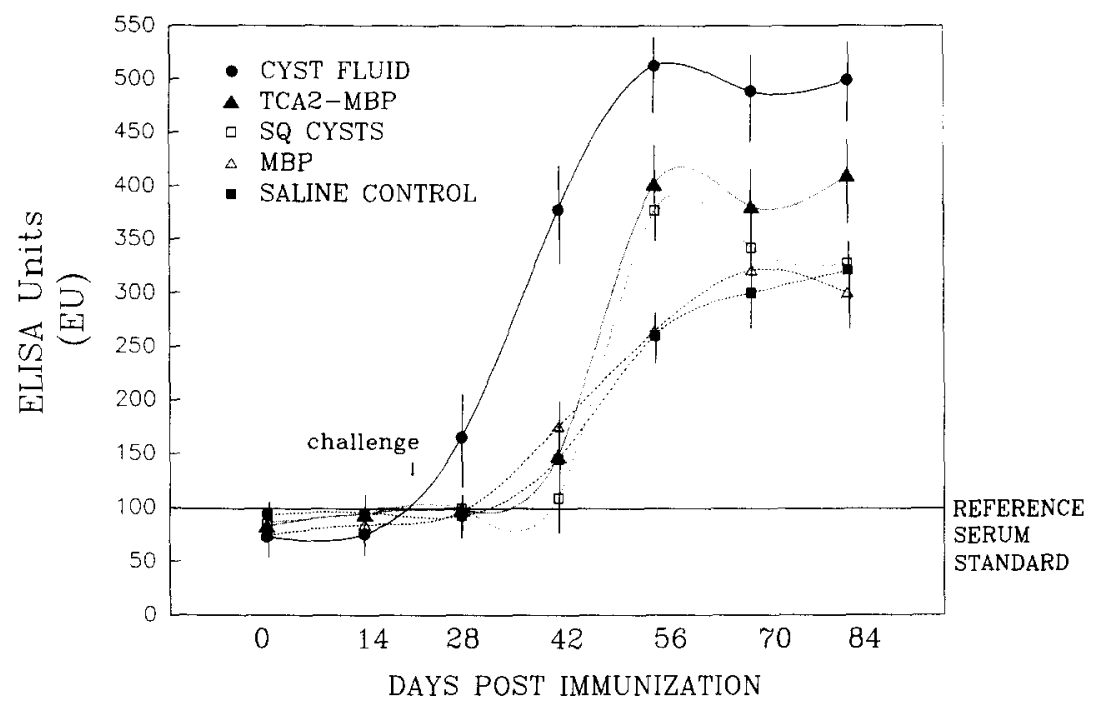

(B) IgG ANTIBODY RESPONSES TO CYST FLUID ANTIGEN FROM SQ IMMUNIZED MICE

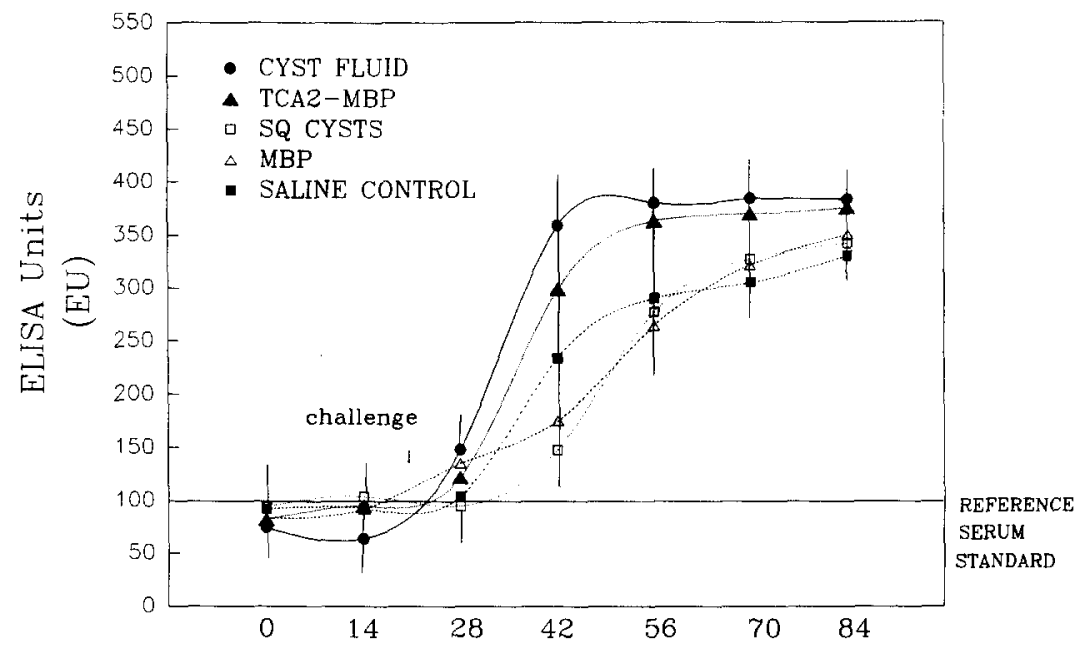

Fig. 2. Total IgG antibody responses to cyst fluid antigen in mice immunized intraperitoneally (IP) (A) or subcutaneously (SQ) (B) in ELISA (pooled sera from each group of ten mice; $X$, SE shown). Horizontal line represents the reference serum standard, defined as serum from non-immunized, unchallenged control mice which was assigned an activity of 100 ELISA enzyme units (EU) per undiluted milliliter. - cyst fluid; $\Lambda$, Taenia crassiceps antigen 2-maltose binding protein (TCA2-MBP); $\square$, SQ cysts; $\triangle, \mathrm{MBP}$; $\square$, saline control. 
(A) Antigen Specific Increases in Antibody Isotypes

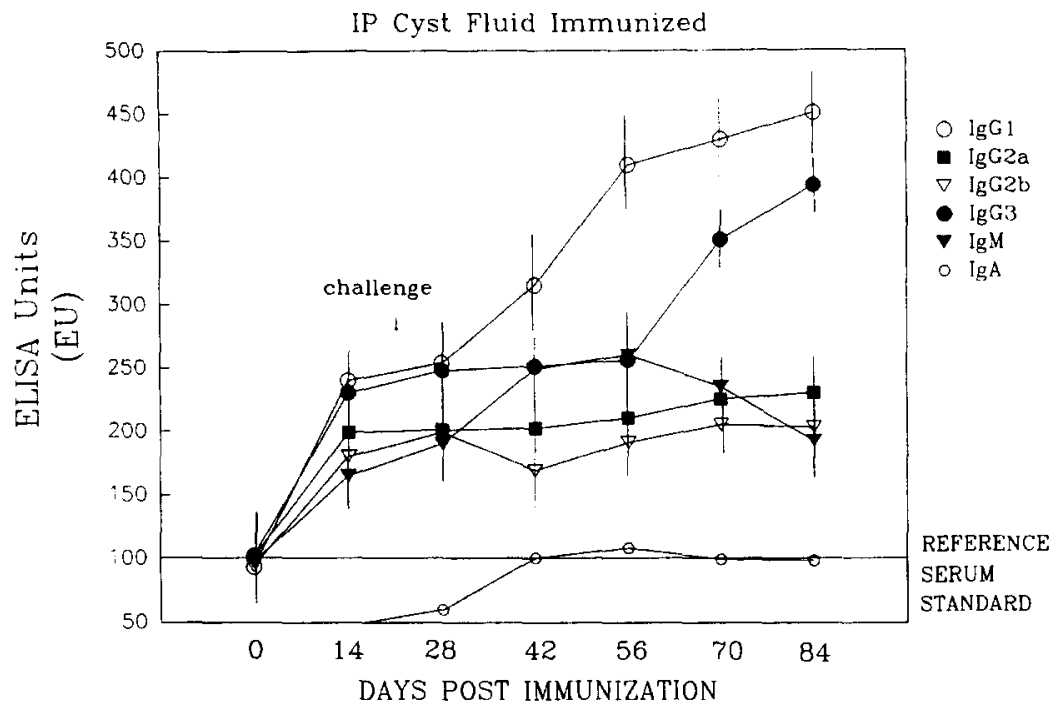

(B) Antigen Specific Increases in Antibody Isotypes

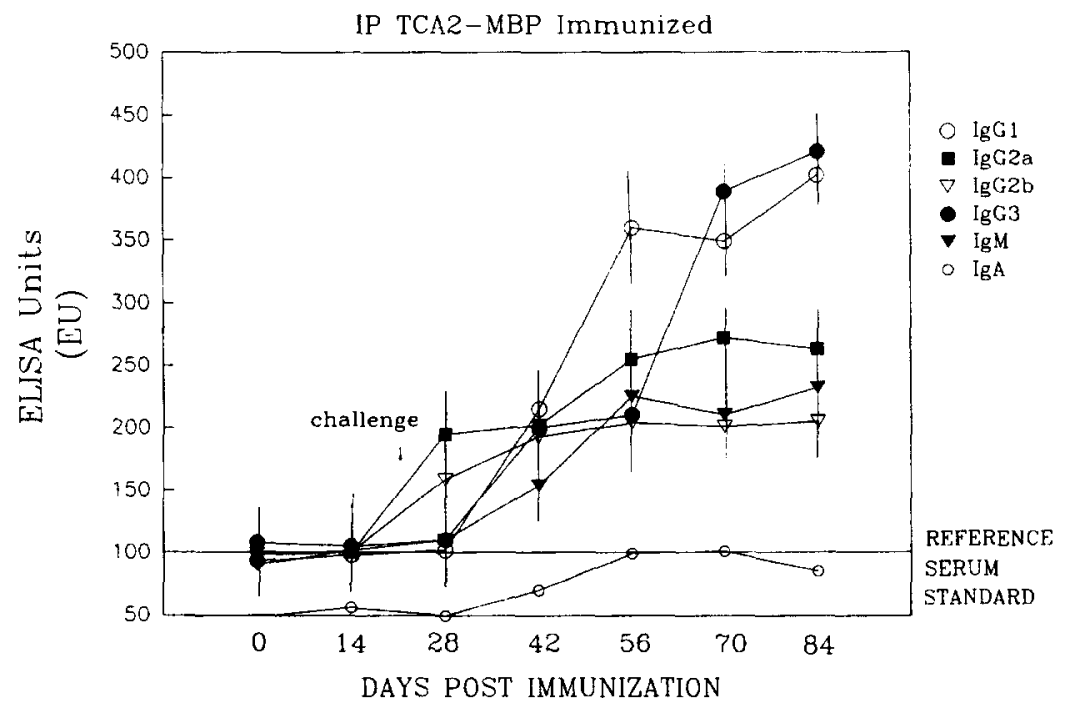

Fig. 3. Antigen-specific increases in antibody isotypes in intraperitoneal (IP) cyst fluid (A), IP Taenia crassiceps antigen 2-maltose binding protein (TCA2-MBP) immunized mice (B); IP saline control-challenged mice (C), over the course of the experiment. Comparison of isotypes between pooled ( $n=10, X$, SE) sera from IP immunized mice, saline control-challenged mice, and isotype levels in reference standard control sera. $\bigcirc, \operatorname{IgG} 1 ; \square, \operatorname{lgG} 2 \mathrm{a} ; \nabla, \operatorname{IgG} 2 \mathrm{~b} ; \bullet, \operatorname{IgG} 3 ; \nabla, \operatorname{IgM} ; \circ, \operatorname{Ig} \mathrm{A}$. 
(C) Antigen Specific Increases in Antibody Isotypes

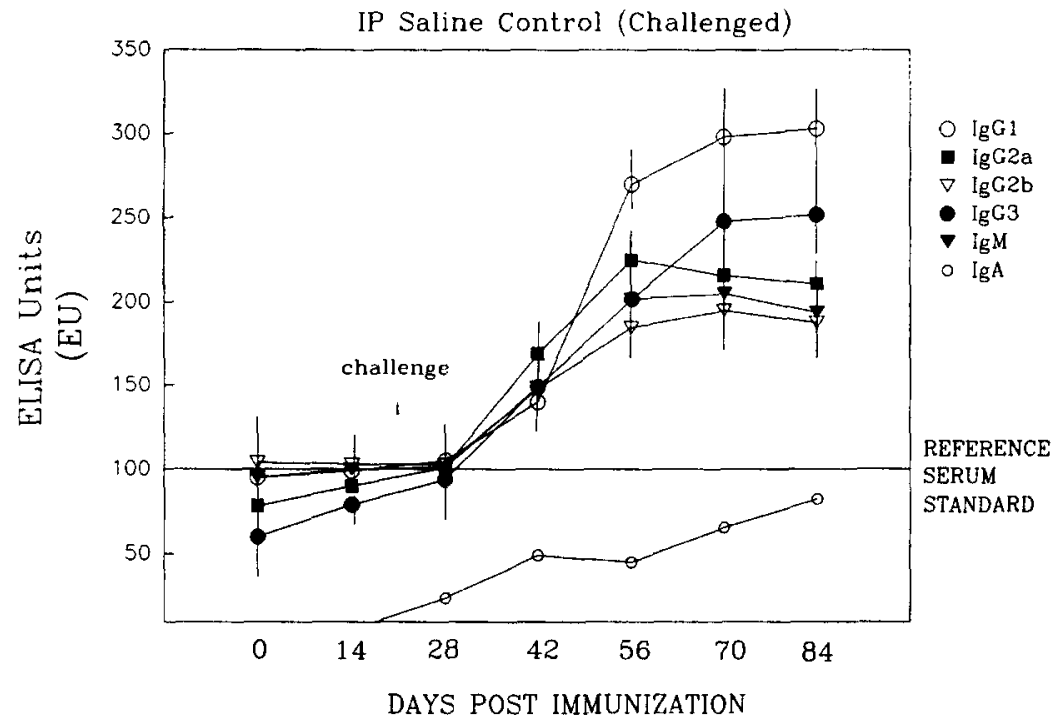

Fig. 3 (continued).

with challenged control animals $(290 \pm 36)$, but these numbers were significantly higher than those seen with IP immunization (Fig. 1B). Immunization with the MBP alone either IP or SQ induced no protective response, with cyst numbers (IP, $278 \pm 42$; SQ, $320 \pm 53$ ) similar to that seen in immunized control animals.

\subsection{Antibody responses}

Total IgG antibody responses which exceeded the RSS (reference standard serum) in mice immunized IP with cyst fluid were seen on day 28 by ELISA (Fig. 2A). Total IgG responses exceeding the RSS to TCA2-MBP and MBP injected IP, or SQ cysts were seen first on day 42 . IgG antibody titers peaked at day 56 except in IP immunized and challenged control animals given MBP and saline. In these two groups, antibody titers peaked at day 70 or continued to rise until necropsy. Total IgG antibody responses were independent of the route of immunization for all groups except the cyst fluid group (Fig. 2B). The IP and SQ immunization resulted in similar total IgG titers in all other groups, but was significantly higher in the IP cyst fluid group when compared with the SQ cyst fluid group.

Increases were seen in serum levels of $T$. crassiceps-specific IgM, IgG1, IgG2a, IgG2b, and IgG3 as early as day 14 in the IP cyst fluid immunized group (Fig. 3A) and in IgG2a and IgG2b on day 28 in the IP TCA2-MBP immunized group (Fig. 3B) when compared with the reference serum standard. No increase in antigen-specific isotype levels was seen in the challenged saline control group (IP, Fig. 3C), the MBP immunized groups, or the SQ cyst group until 3 weeks after the challenge infection (not 
shown). In addition, levels of IgG1 and IgG3 gradually increased over the course of the experiment in all groups, whereas levels of $\operatorname{IgM}, \operatorname{IgG} 2 a, \operatorname{IgG} 2 b$, and $\operatorname{IgA}$ leveled off or decreased.

(A) Eosinophil responses in IP immunized animals

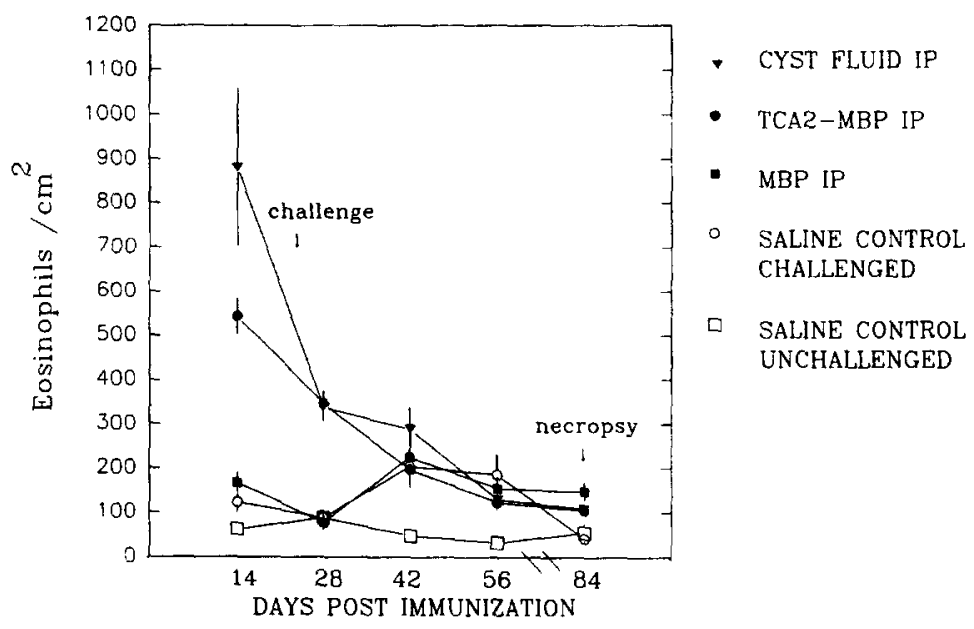

(B) Eosinophil responses in $S Q$ immunized animals

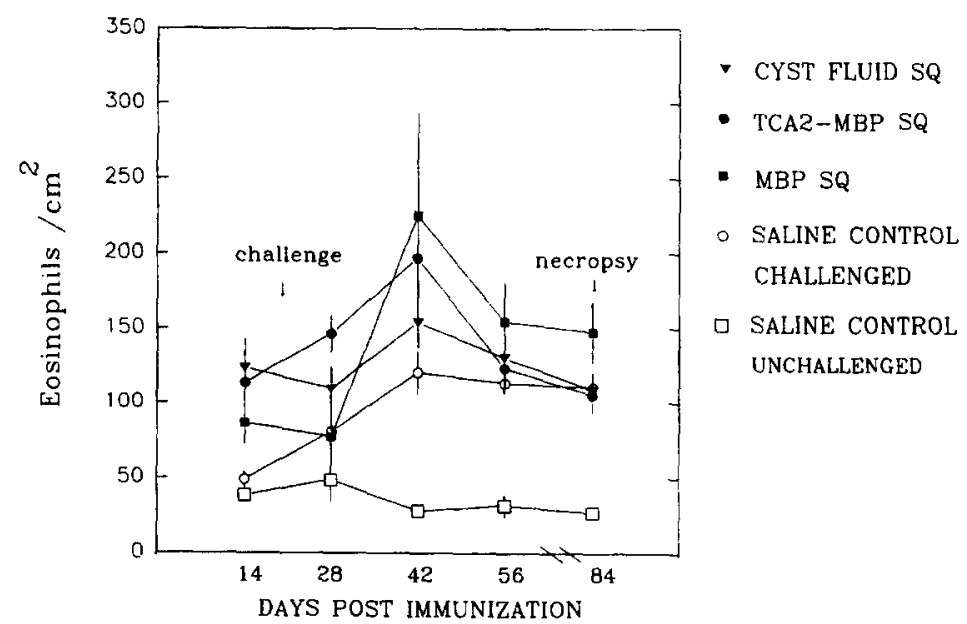

Fig. 4. Peripheral blood eosinophils $\left(\mathrm{cm}^{-2}\right)$ in mice immunized intraperitoneally (IP) (A) and subcutaneously (SQ) (B) from day 14 post injection to necropsy in response to immunization and challenge. $N=10, X, \mathrm{SE}$ shown. $\nabla$, cyst fluid IP; $・$, Taenia crassiceps antigen 2-maltose binding protein (TCA2-MBP) IP;, , MBP IP; ${ }^{\circ}$, saline control-challenged; $\square$, saline control-unchallenged. 


\subsection{Eosinophil responses}

Peripheral blood eosinophil levels were elevated before challenge in those groups immunized IP with cyst fluid or TCA2-MBP (Fig. 4A) but not in SQ immunized animals (Fig. 4B). Eosinophilia was seen at day 14 (the first day surveyed), after which the levels in TCA2-MBP and cyst fluid immunized groups gradually decreased. The dramatic increase in peripheral blood eosinophilia at day 14 was not seen in the groups given SQ cysts, IP or SQ MBP, SQ cyst fluid, SQ TCA2-MBP, or the control groups until after the challenge infection and peaked at day 42 , then decreased over the remainder of the experiment. The increase seen in these groups never approached the levels seen at day 14 in the cyst fluid and TCA2-MBP groups that were immunized IP.

Eosinophils also were found in the peritoneal cavity of animals in all groups at necropsy. There was no correlation between treatment and number of eosinophils, which ranged between 1 and $6 \%$ of the total cell population. The balance of the cell population was made up of lymphocytes (75-80\%) and macrophages (15-19\%).

Granulomas were found in several animals in the immunized groups. The granulomas formed around cysts that were attached to mesenteries or the membrane lining the peritoneal cavity. Sections through the granulomas occasionally revealed the remnants of cyst walls and scoleces. The types of cells that made up the interior of the granulomas could not be determined; however, the exterior often contained lymphocytes and macrophages (not shown).

\section{Discussion}

Immunization of adult female Swiss-Webster mice with TCA2-MBP or with cyst fluid from $T$. crassiceps metacestodes resulted in $93 \%$ and $95 \%$ reduction in the number of peritoneal cysts, respectively, indicating protection against a challenge infection with $T$. crassiceps metacestodes. Intraperitoneal immunization with either bacteria- or parasite-derived antigens has been shown to recruit eosinophils and lymphocytes into the peritoneal cavity (Badley et al., 1988). Siebert et al. (1981) described the rejection of $T$. crassiceps metacestodes in the peritoneal cavity of SQ cyst immunized mice, initially by antibody, and later by cellular encapsulation involving lymphocytes, macrophages, eosinophils, and mast cells.

Peripheral blood eosinophil levels in the cyst fluid and TCA2-MBP IP groups increased before the challenge infection, as did antigen-specific antibody levels. The accelerated recruitment of immediate-type immune effectors such as IgG1, IgG3, eosinophils, and lymphocytes into the peritoneal cavity and systemically by IP immunization with cyst fluid and TCA2-MBP most likely resulted in the destruction of cysts in the challenge inoculum. In addition, the use of alum as an adsorbent for the antigens might have aided in the recruitment of immediate-type immune effectors since alum has been shown to induce immediate-type hypersensitivity responses to adsorbed antigens (Revoltella and Ovary, 1969).

The granulomatous response seen here might mimic the encapsulation response previously described by Siebert and Good (1980). The granulomas were seen most 
frequently in the groups given cyst fluid or the TCA2-MBP IP which exhibited a high degree of protection, suggesting a possible mechanism by which the cysts were attacked and destroyed in these groups.

The similarity in protection induced by the cyst fluid or the TCA2-MBP apparently results from the presence of the native protein in the cyst fluid components. Western blots of total cyst fluid from $T$. crassiceps showed that the native protein is present in a band at $10 \mathrm{kDa}$ (Rhoads et al., 1991) and is recognized by antisera from sheep and cattle infected with $T$. hydatigena and $T$. saginata, respectively (Rhoads et al., 1985; Kamanga-Sollo et al., 1987).

\section{Conclusions}

Various preparations of $T$. crassiceps antigens, cellular lysates as well as whole larval cysts have been used previously as antigens in an attempt to induce immunity to $T$. crassiceps infections in mice with varying results (Siebert and Good, 1980; Kudrna and Prokopic, 1985; Prokopic et al., 1988). The search for a universally protective antigen has been hampered both by non-standardization of antigen preparation among laboratories and the use of inbred strains of mice that exhibit genetic differences in their ability to respond to specific antigens. These problems would be obviated by the use of a genetically engineered antigen such as TCA2-MBP protein, which is protective in an outbred strain of mouse, and testing in the large animal system in which it was to be used. However, its application might be limited if SQ immunization is found not to induce significant protection in large animals as was seen here in Swiss-Webster mice.

\section{Acknowledgements}

The authors wish to thank Yvette Hudson, David Goodman, and Carol Rafter for their able technical assistance, and Marcia Rhoads, Dr. Joseph Urban, and Dr. Patricia Allen for their helpful comments on the manuscript.

\section{References}

Badley, J.E., Grieve, R.B., Rockey, J.H. and Glickman, L.T., 1988. Immune mediated adherence of eosinophils to Toxocara canis infective larvae: The role of excretory-secretory antigens. Parasite Immunol., 9: 133-143.

Del Brutto, O.H. and Sotelo, J., 1988. Neurocysticercosis: An update . Rev. Infect. Dis., 6: $1075-1087$.

Flisser, A. and Larralde, C., 1986. Cysticercosis walls. In: K.F. Walls and P.M. Schantz (Editors), Immunodiagnosis of Parasitic Infections. Academic Press Orlando, FL, pp. 109-161.

Hill, D.E., Fetterer, R.H. and Urban, J.F., Jr., 1990. Biotin as a probe of the surface of Ascaris suum developmental stages. Mol. Biochem. Parasitol., 41: 45-52.

Hill, D.E., Fetterer, R.H., Romanowski, R.D. and Urban, J.F., Jr., 1994. The effect of immunization of pigs with Ascaris suum cuticle components on the development of resistance to parenteral migration during a challenge infection. Vet. Immunol. Immunopathol., 42: 161-169.

Hilwig, R.W. and Cramer, J.D., 1983. In vivo cross reactivity of Taenia saginata and Taenia crassiceps antigens in bovine cysticercosis. Vet. Parasitol., 12: 155-164. 
Kalinna, B., Becker, M. and Geyer, E., 1989. Immunoelectrophoretic analysis of antigens shared by the vesicular fluid and cyst wall of Taenia crassiceps and Taenia saginata metacestodes. Parasitol. Res., 75: 568-574.

Kamanga-Sollo, E.I.P., Rhoads, M.L. and Murrell, K.D., 1987. Evaluation of an antigenic fraction of Taenia hydatigena metacestode cyst fluid for immunodiagnosis of bovine cysticercosis. Am. J. Vet. Res., 48: 1206-1210.

Kudma, K. and Prokopic, J., 1985. Vaccination of mice against Taenia crassiceps infection using living cells prepared from metacestodes. Microbios Lett., 29: 61-63.

Prokopic, J., Kudma, K. and Vanova, L., 1988. Taenia crassiceps: Vaccination of mice against larval infection and comparison of antigens expressed on the surface of inner cells used for vaccination and tegument. Helminthologia, 25: 263-271.

Peterman, J.H. and Butler, J.E., 1989. Application of theoretical considerations to the analysis of ELISA data. Biotechniques, 7(6): 1989 608-615.

Revoltella, R. and Ovary, Z., 1969. Preferential production of rabbit reaginic antibodies. Int. Arch. Allergy Appl. Immunol., 36: 282.

Rhoads, M.L., Murrell, K.D., Dilling, G.W., Wong, M.M. and Baker, N.F., 1985. A potential diagnostic reagent for bovine cysticercosis. J. Parasitol., 71: 779_-787.

Rhoads, M.L., Zarlenga, D.S. and Al-Yaman, F.M., 1991. A recombinant immunodiagnostic antigen for bovine cysticercosis. Southeast Asian J. Trop. Med. Public Health, 22 (Suppl.): 268-270.

Siebert, A.E. and Good, A.H., 1980. Taenia crassiceps: Immunity to metacestodes in BALB/c and BDF1 mice. Exp. Parasitol., 50: 437-446.

Siebert, A.E., Blitz, R.R., Morita, C.T. and Good, A.H., 1981. Taenia crassiceps: Serum and surface immunoglobulins in metacestode infections of mice. Exp. Parasitol., 51: 418-430. 